\title{
MECANISMOS DE SECAGEM VISANDO A REDUÇÃO DE UMIDADE EM SINTER FEED DE MINÉRIO DE FERRO*
}

\section{Resumo}

Thiago Cesar de Souza Pinto ${ }^{1}$ Deovaldo de Moraes Junior ${ }^{2}$ Luís Renato Bastos $\mathrm{Lia}^{3}$

Os teores de umidade $(U)$ presente no minério de ferro, após o processamento mineral, se torna uma dificuldade para seu transporte marítimo à medida que este teor ultrapassar os limites de TML (Transportable Limit Moisture). O presente trabalho teve por objetivo a identificação dos mecanismos de secagem em concentrados de minério de ferro tipo sínter feed em unidade experimental de secador de bandejas em escala de laboratório. São apresentados e discutidos resultados em que os mecanismos identificados se revelam como água livre superficial e capilaridade, para a faixa de umidade de interesse $(13<\mathrm{U}<6 \%)$. Uma regressão não linear foi realizada identificando o peso das variáveis em estudo, permitindo assim um modelamento dos resultados de redução de umidade. $O$ modelo apresentou boa aderência aos resultados experimentais com desvios menores que $10 \%$ entre os dados previstos e observados.

Palavras-chave: Minério de ferro; TML; Umidade; Transporte marítimo.

\section{DRYING MECHANISMS AIMING AT IRON ORE SINTER FEED MOISTURE REDUCING}

\section{Abstract}

The iron ore moisture grades, at the end of processing plant, become an issue to the maritime freight as the TML rates are exceeded. The present work aimed at determining the drying mechanisms for the sinter feed iron ore using an experimental apparatus of tray dryer in laboratory scale. The results are presented and discussed where the identified mechanisms are superficial water and capillarity, for the range of interest $(13 \%<\mathrm{U}<6 \%)$. A modeling has been proposed to identify the effect of each related variable. The deviation of the experimental modeling presented a good adherence to the experimental data with a deviation less than $10 \%$.

Keywords: Iron ore; TML; Moisture; Maritime freight.

1 Eng. Químico, M.Sc, Ph.D. Pesquisador do Instituto Tecnológico Vale (ITV-MI), Ouro Preto, MG, Brasil.

2 Eng. Químico, M.Sc, Ph.D. Coordenador do laboratório de Operações Unitárias, Engenharia química, Universidade Santa Cecília, Santos, SP, Brasil.

3 Eng. Químico, M.Sc, Ph.D. Coordenador do curso de Eng. Química, Universidade Santa Cecília, Santos, SP, Brasil.

4 Eng. de Minas, M.Sc, Ph.D. Diretor Científico do Instituto Tecnológico Vale (ITV-MI), Ouro Preto, MG, Brasil. 


\section{INTRODUÇÃO}

O Brasil apresentou em 2014, uma movimentação de cargas portuárias de minério de ferro na ordem de 345,5 milhões de toneladas. Tal volume representou um crescimento em torno de $5 \%$ em relação ao ano de 2013. Neste cenário, quase $62 \%$ do total movimentado foram a partir dos terminais de Ponta da Madeira $(32,2 \%)$ e de Tubarão $(29,4 \%)$ [1].

Dentro deste cenário, a importância do teor de umidade apresentado pelo minério de ferro no momento do embarque se mostra de suma importância já que é desejável o mínimo de água e o máximo de minério de ferro visando o aumento de ganhos potenciais. Assim, o controle do teor de umidade no minério se revela um importante fator, tanto em termos de volume de minério a ser transportado bem como operacionalidade de embarque, visando atender regulamentações internacionais para o limite de umidade permitido.

O teor de umidade do minério de ferro apresenta controles internacionais com base no parâmetro de TML (Transportable Moisture Limit). Valores de umidade acima do TML podem trazer danos à embarcação e em situações extremas levar o navio a adernar. O Brasil apresenta pequenas diferenças no limite deste parâmetro de controle conforme a região, porém a maior magnitude se apresenta para TML de $10,45 \%$. Caso a umidade avaliada no embarque seja superior ao limite local de TML, fica vedada a continuidade do embarque, acarretando atrasos na operação, problemas com estocagem do minério, dentre outros, trazendo significativos atrasos e danos. Desta forma, com o custo do frete marítimo sendo uma das modalidades mais caras do setor logístico, o transporte de água associado ao minério de ferro pode vir a limitar as operações de embarque bem como a massa total de minério a ser transportada.

A secagem se trata da remoção de pequenas quantidades de água ou outros líquidos de materiais sólidos na forma de vapor. O processo de secagem pode se dar com o contato direto do gás secante e a água a ser removida, sob condições de pressão negativa (vácuo) ou ainda pelo contato do calor adicionado de forma indireta com o líquido a ser removido [2].

A umidade de uma mistura de vapor ar-água pode ser definida com a massa $(\mathrm{kg}) \mathrm{de}$ vapor de água contida em $1 \mathrm{~kg}$ de ar seco, sendo assim dependente somente da pressão parcial de vapor de água no ar e da pressão total [2,3]. Se utilizando as massas molares da água e do ar, pode-se definir a umidade conforme Equação 1. Já a umidade relativa pode ser definida conforme Equação 2.

Em que:

$$
H=\frac{18,02}{28,97} \frac{p_{A}}{P-p_{A}}
$$

H é a umidade, em kg de água por kg de ar seco;

$\boldsymbol{p}_{\boldsymbol{A}}$ é a pressão parcial de água [kPa];

$\mathrm{P}$ é a pressão total [kPa].

Sendo:

$$
H_{R}=100 \frac{p_{A}}{p_{A S}}
$$

$\boldsymbol{p}_{\boldsymbol{A} S}$ a pressão da água pura na referida temperatura

$\boldsymbol{H}_{\boldsymbol{R}}$ a umidade relativa, \% 
O movimento da umidade, quando do contato entre um leito de sólidos úmido e o fluxo de um gás secante e não saturado, inicia-se com o ajuste de temperatura do corpo sólido com a temperatura de bulbo úmido do meio secante. Os mecanismos da remoção da umidade se iniciam por um período a taxa constante, em que a remoção de água pela superfície ocorre sem sofrer influência do sólido e a taxa de evaporação é, essencialmente, a mesma de um processo convencional de evaporação de uma massa de líquido livre. Durante esse período, a massa de líquido subtraída da superfície é substituída, continuamente, pelo líquido que se desloca por capilaridade a partir do interior do material, mantendo constante a taxa de remoção de umidade. Quando do aparecimento do primeiro ponto seco em sua superfície, a velocidade da água do material em direção à superfície sofre uma redução, iniciando-se o período a taxa decrescente. Materiais compostos por sólidos granulados ou cristalinos conservam a umidade nos interstícios existentes entre as partículas ou em poros superficiais rasos e abertos. Nessas estruturas, o movimento da umidade é relativamente livre e ocorre em consequência da interação das forças gravitacionais e das forças de tensão superficial (capilares), regidos pelo número adimensional de Bond [2,3]. A Figura 1 apresenta os mecanismos de secagem para esta classe de materiais.

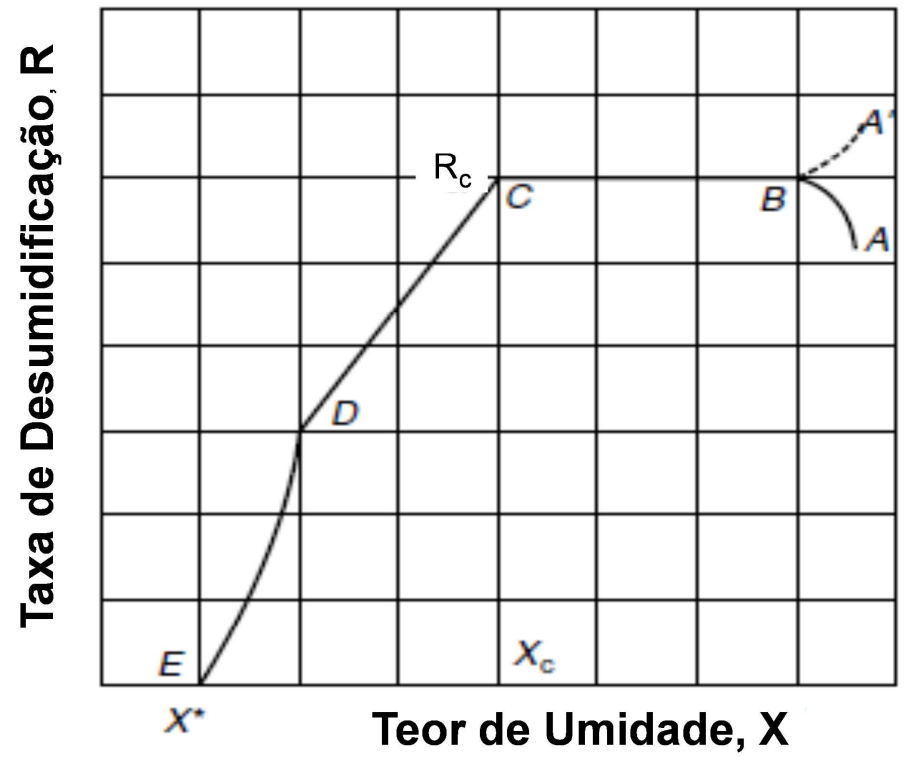

Figura 1: Curva de desumidificação típica para uma dada condição, em que $A B$ representa o período de aquecimento do sólido até a temperatura do bulbo úmido do gás; $B C$ é período à taxa de desumidificação constante (evaporação da água superficial), sendo $C$ o ponto crítico; CD contempla o período à taxa decrescente regido pelo mecanismo da capilaridade; $\mathrm{D}$ indica o segundo ponto crítico e mudança no mecanismo para a difusão; Adaptado de [2,3].

A identificação de mecanismos de secagem para pellets de oxido de ferro tem sido reportada na literatura corrente nos últimos 20 anos. No passado, modelos mais simples da taxa de secagem $(R)$ relatavam a secagem em um único mecanismo, porém a maioria destes modelos não foram validados [4]. Estudos na década de 80 revelaram que os mecanismos de secagem em pellets de oxido ferro ocorriam em mais de um estágio [4-6]. A maioria destes estudos convergem sobre a existência de 2 mecanismos de secagem, sendo um a taxa constante e outro a taxa decrescente, em que são identificados a remoção da água através do filme líquido na superfície e de forças capilares. São reportados também a existência de um terceiro mecanismos, regido pela difusão, porém este mecanismo, na maioria dos casos é 
negligenciado pois se trata de umidade a nível de poros das partículas e água higroscópica [5]. Em 2011, foi apresentado um trabalho em que se utilizou a simulação de secagem em pellets de óxido de ferro utilizando a ferramenta de CFD (Computational Fluid Dynamics) e os resultados corroboraram com os modelos obtidos com validação experimental [5].

\section{MATERIAIS E MÉTODOS}

\subsection{Materiais}

A unidade experimental utilizada neste estudo está disposta no Laboratório de Operações Unitárias da Universidade Santa Cecília, e é apresentada na Figura 2. A bancada é composta de um túnel de seção quadrada $145 \times 145 \mathrm{~mm}$ e comprimento $2300 \mathrm{~mm}$, em acrílico, onde se promoveu a passagem de ar a partir da sucção de um ventilador do tipo Siroco, acoplado a montante da estrutura. Um ciclo de refrigeração externo, utilizando R12 como fluido refrigerante, teve seu evaporador alocado interna e perpendicularmente ao duto para provocar a condensação de parte da água presente no ar e, consequentemente, gerar ar mais seco. A umidade relativa do ar no momento dos testes era de $\mathrm{H}_{\mathrm{R}}=40 \%$. Um sistema de resistências elétricas, com controle manual de potência, foi inserido de forma análoga para proporcionar variação de temperatura do ar. A jusante do duto, um suporte lateral acomodou, de forma centralizada, as bandejas contendo as amostras de minério. Um conjunto de 4 termômetros, para leitura das temperaturas de bulbo seco e de bulbo úmido, forneceu os dados necessários para a determinação da umidade relativa e da umidade absoluta do ar através de carta psicrométrica apropriada. Finalmente, um ar condicionado de $10.000 \mathrm{Btu} / \mathrm{h}$ foi utilizado para geração de ar com baixa umidade. A Figura 3 apresenta o acondicionamento do sínter feed de minério de ferro em bandejas de diferentes espessuras. O material utilizado foi o sínter feed de minério de ferro com granulometria que apresentou um tamanho máximo de $10 \mathrm{~mm}$.

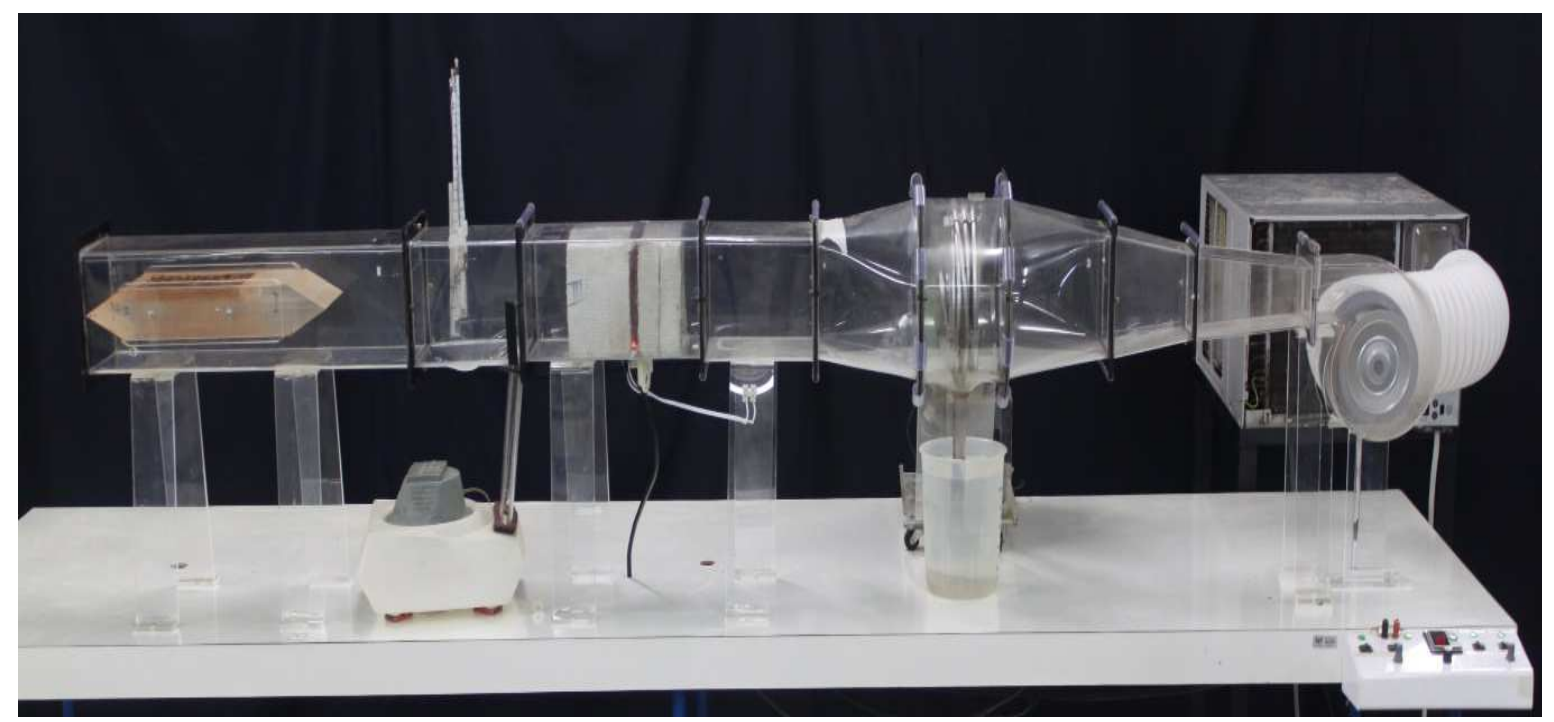

Figura 2: Vista frontal da unidade experimental para estudo da desumidificação de sólidos na condição estática (Bandeja). 


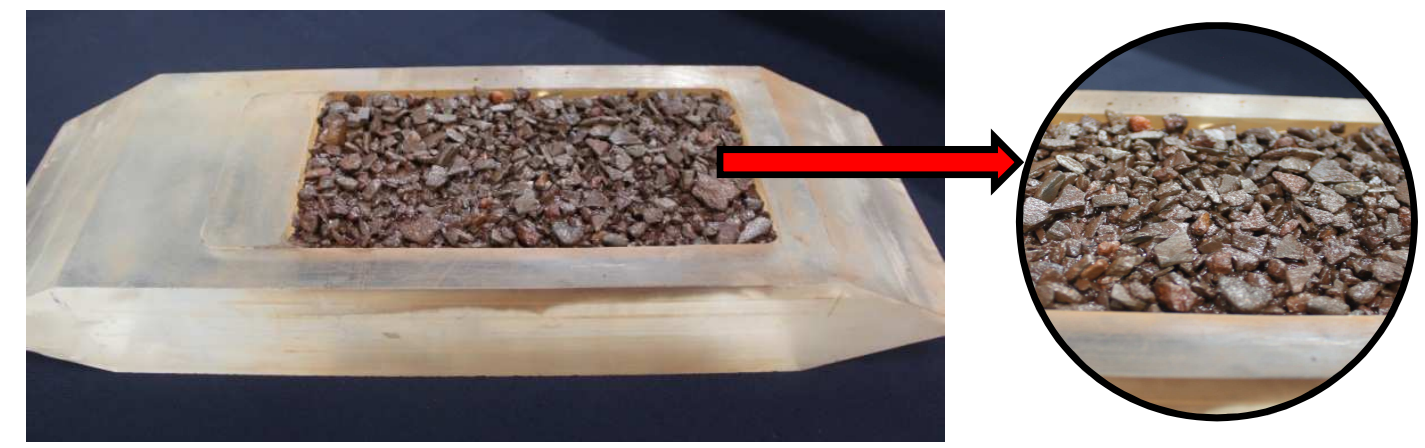

Figura 3: Vista do acondicionamento de sólidos na bandeja de secagem.

\subsection{Métodos}

A preparação da amostra para a condição experimental se deu com a determinação da massa inicial do conjunto bandeja-minério numa balança de precisão. Quando da inserção da bandeja no túnel de secagem, iniciou-se o monitoramento do tempo. Os intervalos para verificação da massa total do conjunto foram fixados em 5 minutos. Também foram realizadas leituras da temperatura. As condições de contorno dos ensaios de secagem se apresentaram conforme descrito na Tabela 1. A curva de densidade aparente em função da umidade também foi determinada para o sínter feed de minério de ferro em estudo. Para tanto se utilizou um cilindro de volume conhecido, em que foi preenchido com o minério em diferentes umidades e teve sua massa monitorada. Esta curva também permite a identificação dos limites de água presentes no minério em estudo.

Tabela 1: Condições experimentais para ensaios de redução de umidade em sinter feed de minério de ferro.

\begin{tabular}{c|c|c|c}
\cline { 2 - 4 } & $\begin{array}{c}\text { Temperatura } \\
\left({ }^{\circ} \mathbf{C}\right)\end{array}$ & $\begin{array}{c}\text { Velocidade do Ar } \\
(\mathbf{m} / \mathbf{s})\end{array}$ & $\begin{array}{c}\text { Espessura da Bandeja } \\
(\mathbf{m m})\end{array}$ \\
\hline \multirow{4}{*}{ Níveis } & & & 15 \\
& 25 & 5,0 & 30 \\
& 30 & 7,0 & 45 \\
& 40 & & 60 \\
\hline
\end{tabular}

\section{RESULTADOS E DISCUSSÃO}

A Figura 4 apresenta as curvas tipo Dry bone, em que se apresentam a Taxa de desumidificação $(R)$ em função da umidade para uma dada condição. Estas curvas foram obtidas para todas as condições experimentais.

Pode-se verificar que o minério de ferro do tipo sinter feed apresentou uma pequena zona de aclimatação inicial, em que houve uma taxa de retirada de água de forma potencializada. Após este breve período, iniciou-se a zona à taxa constante até o alcance do primeiro ponto crítico, em torno de $6 \%$. Então, seguiram-se os períodos à taxa decrescente até que fosse atingida a umidade de equilíbrio. É possível observar que para a condição proposta na Figura 4, todas as curvas apresentaram comportamento semelhante, em que é possível verificar as descontinuidades na curva que identificam os mecanismos de taxa constante (água superficial), capilaridade e difusão, sendo este último mecanismo identificado para umidades 
aproximadamente abaixo de 4\%. A taxa de secagem observada para o período constante apresentou diferenças em função da espessura das bandejas, sendo que para espessuras de $15 \mathrm{~mm}$ e $30 \mathrm{~mm}$ foram encontradas taxas de maior magnitude em função da menor espessura, quando comparadas com as espessuras de $45 \mathrm{~mm}$ e $60 \mathrm{~mm}$.

A Figura 5 apresenta as taxas de secagem em função da umidade do sínter feed de minério de ferro para a espessura de bandeja de $60 \mathrm{~mm}$, onde se analisou o efeito da temperatura. É possível observar que com o aumento da temperatura é possível se obter taxas de desumidificação maiores. $\mathrm{O}$ aumento da temperatura de $25^{\circ} \mathrm{C}$ para $40^{\circ} \mathrm{C}$ apresentou um aumento na taxa de desumidificação em torno de $59 \%$.
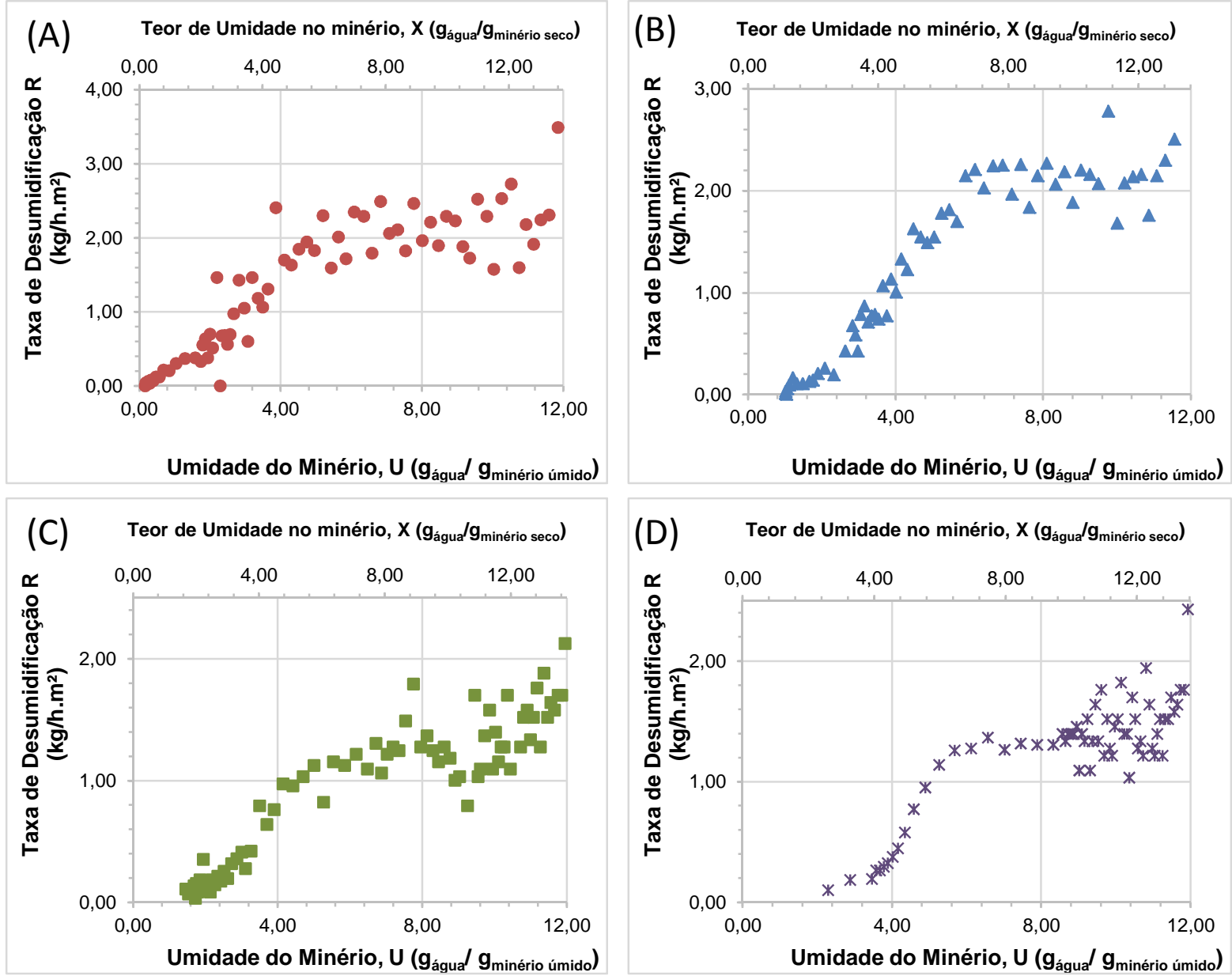

Figura 4: Evolução da taxa de desumidificação com a diminuição da umidade do material. Condições do ensaio: Temperatura de $25^{\circ} \mathrm{C}$, ar com $40 \%$ de umidade relativa e velocidade do ar de $7,0 \mathrm{~m} / \mathrm{s}$. A) Bandeja $15 \mathrm{~mm}$, B) Bandeja $30 \mathrm{~mm}$, C) Bandeja $45 \mathrm{~mm}$ e D) Bandeja $60 \mathrm{~mm}$. 
Teor de Umidade no minério, $\mathrm{X}$ ( $\mathrm{g}_{\text {água }} / \mathrm{g}_{\text {minério seco }}$ )

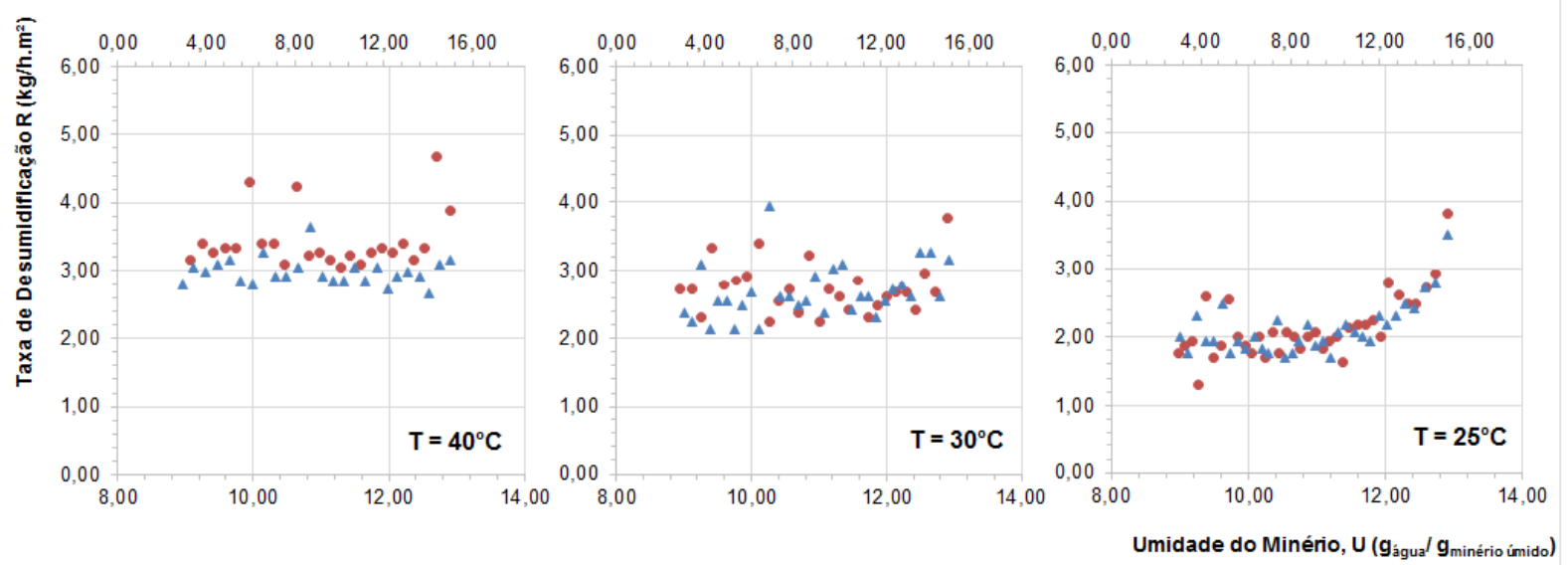

Figura 5: Curva da taxa de secagem em função da umidade do minério para bandeja de $60 \mathrm{~mm}$, velocidade do ar de $7,0 \mathrm{~m} / \mathrm{s}$.

A Figura 6 apresenta a Taxa de desumidificação em função da espessura do leito utilizado. Os resultados corroboram com o exposto em literatura [2] [3] [6], em que a taxa de desumidificação apresenta aumento significativo com 0 aumento da temperatura do ar.

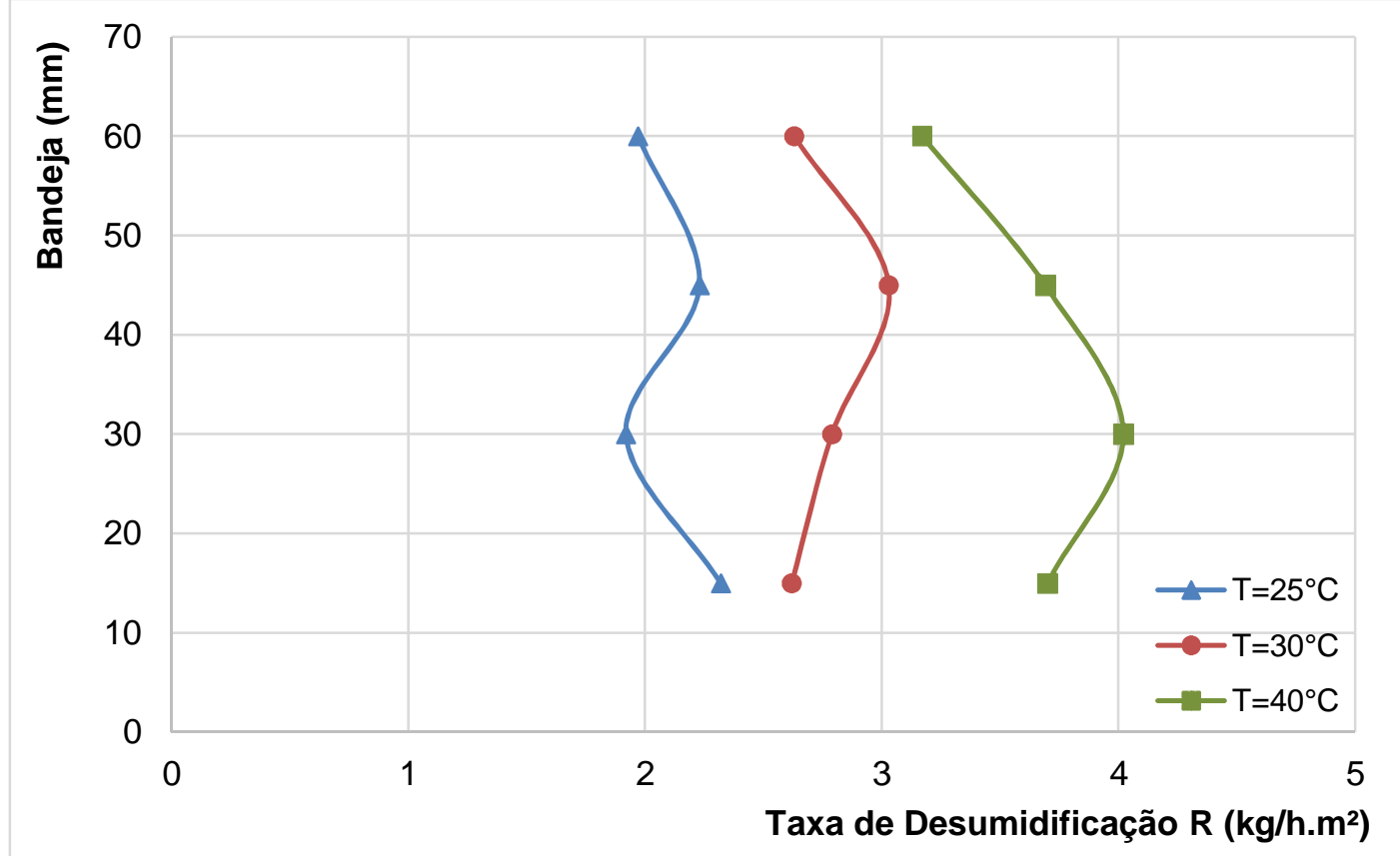

Figura 6: Efeito da espessura do leito de minério na taxa de desumidificação, para velocidade do ar de $7 \mathrm{~m} / \mathrm{s}$, a umidade absoluta do ar de 0,009 $\pm 0,001 \mathrm{~kg}$ água $/ \mathrm{kg}$ ar seco e umidade inicial de $13 \mathrm{e}$ final de $6 \%$.

A Figura 7 traz os resultados da densidade aparente em função da umidade do minério de ferro tipo sínter feed. De acordo com o apresentado na figura, é possível analisar que os teores de umidade em que se encontram água intersticial se apresentam nos limites de $6 \%$ a $20 \%$ de umidade. Tais resultados corroboram com as curvas tipo Dry Bone, em que a umidade crítica, isto é, o ponto em que o regime passa a operar em taxa decrescente se apresentam em umidade em torno de $6 \%$. 


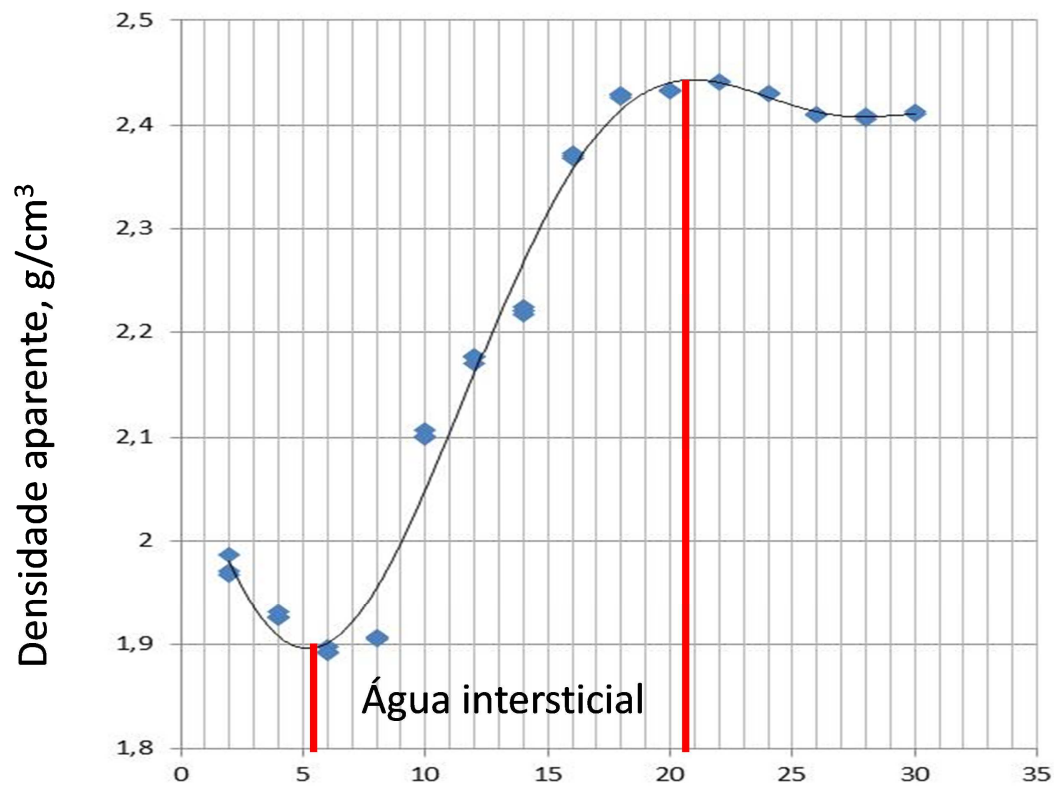

Umidade, \%

Figura 7: Densidade aparente em função da umidade de sínter feed de minério de ferro.

Com base nos resultados experimentais, foi realizada uma regressão não linear para o modelamento dos dados visando obter aderência aos dados obtidos experimentalmente. O modelo visou entender a redução da umidade do sínter feed de minério de ferro indicando o peso de cada variável no processo, analisadas de acordo com a magnitude de seus expoentes. A Equação 3 apresenta o modelo gerado a partir dos resultados experimentais. A variável tempo foi inferida como variável resposta para a taxa de desumidificação de $13 \%$ para $6 \%$. O desvio do modelo se aplica para as condições propostas neste estudo.

$$
\Delta U=1,053 . T^{0,3068} v^{0,178} e^{-0,166} t^{0,130}
$$

Em que:

$\Delta \boldsymbol{U}$ é a variação de umidade, \%

T é a temperatura, ${ }^{\circ} \mathrm{C}$

v é a velocidade do ar, $\mathrm{m} / \mathrm{s}$

e é a espessura do leito, $\mathrm{mm}$

t é o tempo, min.

A curva de paridade entre os dados preditos e observados é apresentada na Figura 8. É possível observar que os dados previstos apresentam boa correlação com os dados experimentais com desvios menores que $10 \%$. 


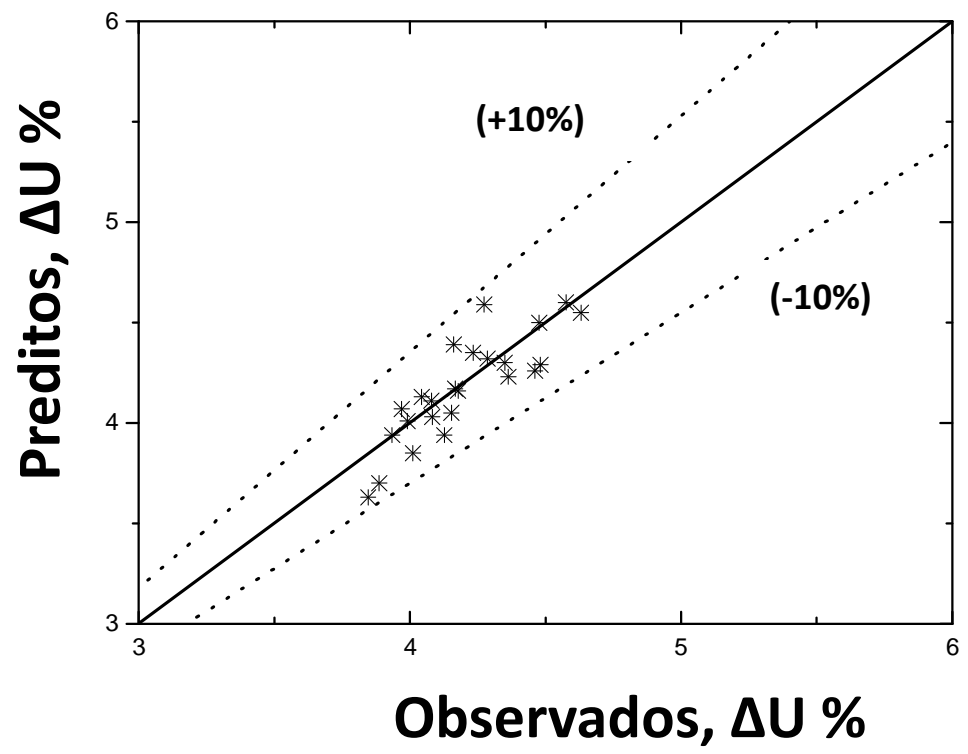

Figura 8: Curva de paridade entre os dados de redução de umidade experimentais e preditos.

\section{CONCLUSÃo}

O objetivo deste trabalho foi a identificação de mecanismos de secagem do sínter feed de minério de ferro com tamanho máximo de $10 \mathrm{~mm}$. A unidade experimental utilizada permitiu a realização de ensaios de desumidificação identificando a presença de 3 mecanismos: Água livre ou superficial, capilaridade e difusão, identificados pela descontinuidade das curvas da taxa de secagem em função da umidade. Os mecanismos identificados corroboram com os dados apresentados em literatura corrente. Para a faixa de interesse de umidade $(13 \% \bigcup<6 \%)$ foi possível identificar que os mecanismos de água livre e capilaridade são imperativos, sendo possível analisar que a remoção de água dentro destes níveis de umidade se apresenta de forma facilitada em função dos mecanismos identificados. O modelo proposto para a reprodução dos dados experimentais apresentou boa aderência, com desvios menores que $10 \%$, revelando a ordem de significância decrescente das variáveis estudadas $(T>v>e>t)$.

\section{REFERÊNCIAS}

1 ANTAQ. Boletim Anual de Movimentação de Cargas - 2014. Análise da Movimentação de Cargas nos Portos Organizados e Terminais de Uso Privado. Brasília, 2015.

2 Geankoplis, C. J. Transport Processes and Unit Operations. 4a ed. New Jersey, PTR Prentice Hall, 2003. 1025p.

3 Foust, A. S., Wenzel, L. A., Clump, C. W., Maus, L., Andersen, L. B. Princípios de Operações Unitárias. Rio de Janeiro, LTC, 1982. 670p.

4 Mccabe, W. L., Smith, J. C., Harriott, P. Unit Operations of Chemical Engineering. 7a ed. International Edition printed in Singapore, McGraw-Hill, 2005. 1140p.

5 Tsukerman, T., Duchesne, C., Hodouin, D. On the drying rates of individual iron oxide pellets. International Journal of Mineral Processing, Volume 83, pag 99-115, 2007.

6 Ljung, A-L., A.-L. Lundström, T. S., Marjavaara, B. D., Tano, K. Convective drying of an individual iron ore pellet - Analysis with CFD. International Journal of Heat and Mass Transfer. Volume 54, pag 3882-3290, 2011. 